\title{
Atienza, Manuel. Una apología del Derecho y otros ensayos. Madrid: Trotta, 2020.
}

\author{
Roberta Simões Nascimento \\ Universidad de Brasília
}

Fecha de recepción 10/03/2021 I De publicación: 24/06/2021

Con una feliz metáfora que tomo prestada de Francisco Laporta se puede hacer referencia a la teoría de Manuel Atienza como una matrioska (el conjunto de muñequillas rusas de madera que se pueden colocar una dentro de la otra, en perfecto ajuste y obra de arte), en el sentido de que, en realidad, varias teorías se han ido incorporando a la propuesta del catedrático español, cuyas ideas tienen gran trascendencia en Brasil.

De hecho, una de las principales características de la construcción teórica de Manuel Atienza es precisamente el sincretismo, en la medida en que su teoría simbolizaría una especie de aleación metálica formada por las aportaciones de varios autores que le precedieron así como de sus contemporáneos (como Viehweg, Perelman, Toulmin, MacCormick, Alexy, Dworkin, Peczenik, Aarnio, Summers, Siches, Nino, Carrió, Alchourrón, Bulygin, entre otros).

Lejos de cualquier significado negativo que pudiera suscitar algún tipo de sincretismo ${ }^{1}$, uno de los grandes méritos (y la propia originalidad) de Manuel Atienza está precisamente en ordenar metodológicamente todos los elementos de esta amalgama (recogiendo todo lo valioso de las construcciones teóricas anteriores, integrándolas en una más satisfactoria que el positivismo jurídico) y en atribuir un fin, una finalidad, al Derecho. Atienza consigue así dar sentido a las tareas jurídicas.El autor lo viene haciendo a pequeños (y grandes) pasos desde 1991 con la publicación de Las razones del derecho, donde presentó el primer esbozo de su teoría de la argumentación jurídica, señalando las críticas y los déficits de lo que denominó teoría estándar de la argumentación jurídica (categoría que él mismo propuso para referirse a los trabajos de MacCormick y Alexy).

\footnotetext{
${ }^{1}$ Sobre el tema: SILVA, Virgílio Afonso da. Interpretação constitucional e sincretismo metodológico. In: SILVA, Virgílio Afonso da (Org.). Interpretação constitucional. São Paulo: Malheiros, 2005, pp. 115-143.
} 
Ya en esa época - hay que destacarlo - es posible advertir la preocupación de Manuel Atienza por la necesidad de que la teoría cumpla una "función práctica", es decir, que sea capaz de ofrecer una orientación útil a las tareas de producción, interpretación y aplicación del Derecho, incluida la de mejorar la formación jurídica (para que los alumnos aprendan a pensar o razonar como un jurista, con sentido crítico, sin limitarse al conocimiento del Derecho positivo).

Con el paso de los años publicó El sentido del derecho (2001) y El derecho como argumentación (2006) hasta culminar en el colosal Curso de argumentación jurídica (2013) donde compila los "materiales" (fragmentos transcritos de los autores fundamentales que escoge el propio Atienza por constituir el material "básico" de lectura necesaria para ser un buen jurista).

Más recientemente, escribió Filosofía del derecho y transformación social (de 2017), Comentarios e incitaciones (de 2019) - que merecerían cada cual reseñas dedicadas en exclusiva -, sin olvidar sus innumerables escritos en periódicos, revistas y obras colectivas.

En su último libro, Una apología del derecho y otros ensayos (de 2020), Manuel Atienza regala a los lectores una recopilación de diez ensayos sobre temas diversos (el papel de la enseñanza del Derecho en las universidades, el activismo judicial, los derechos humanos, el Derecho y la literatura, la filosofía del derecho, la ponderación, entre otros) sin pretensión de sistematicidad, lo que es advertido por el propio autor quien, en la presentación, invita al lector a leerlo en el orden que mejor le parezca.

Sin embargo, hay un claro hilo conductor en todos los capítulos: el propósito del autor de presentar el Derecho como una "empresa esencialmente problemática, abierta, que exige dosis considerables de imaginación, notables recursos teóricos, formación y entereza moral, y que resulta crucial para comprender el mundo social y contribuir a su transformación” (p. 15).

En el primer ensayo (Una apología del derecho, que da título al libro), Manuel Atienza construye una especie de ficción distópica: un diálogo que tiene lugar en el año 2048 durante una reunión en una Universidad española en la que se discute la necesidad de la enseñanza del Derecho a todos los universitarios.

Los que conocen más de cerca al profesor Manuel Atienza saben que la creciente "burrocratización" (con doble 'r' para enfatizar el aumento de la 'estupidez') de la Universidad española (y la brasileña va por el mismo camino) es uno de los temas que más le indigna. 
Así, en medio de la crítica sobre las tendencias irracionales y mercantilizadoras de la Universidad que aparecen en el diálogo imaginario, Manuel Atienza expone sus ideas jurídicas utilizando excelentes recursos literarios. Hace una apología sobre la necesidad del Derecho, en un brillante ejemplo de obra de teatro con riqueza literaria y jurídica al mismo tiempo - similar a lo que hizo Rudolf von Ihering en En el cielo de los conceptos jurídicos, que es sin duda una de sus fuentes de inspiración.

Al tiempo que rescata históricamente la pretensión idílica de construir un orden social que no necesite recurrir al Derecho, pasando incluso por el posthumanismo y el transhumanismo, el autor se encarga de rechazar que las sociedades puedan vivir sin Derecho, mostrando la necesidad del "sistema de fines" que es el Derecho, cuya consecución requiere el uso de determinados medios, siendo uno de ellos las normas coactivas (coercitivas), que, aunque no forman parte de la esencia del Derecho, son una necesidad práctica del sistema jurídico.

A continuación, Atienza explica que los fines del Derecho "han ido variando a lo largo de la historia, pero, en el marco del Estado constitucional, se identifican con los grandes valores del humanismo y de la Ilustración: la igualdad, la libertad y la dignidad” (p. 27). Reconoce que “nuestros Derechos no nos proveen de esos bienes más que en una medida limitada y, en ocasiones (o para algunos), casi en ninguna medida”, por lo que afirma que "el Derecho simplemente no es la justicia”. A continuación, Atienza lleva al lector a su argumento de que "estos valores [la igualdad, la libertad y la dignidad] no tendrían ninguna posibilidad de verse realizados (ni siquiera en esa forma tan insuficiente) sin la existencia el Derecho”.

De ello resulta su defensa de la unidad de los tres componentes fundamentales de la razón práctica: el Derecho, la moral y la política. Con sus propias palabras: "lo que fundamenta el Derecho, en último término, no puede ser más que la moral, y sin el poder político (estatal o no) el Derecho no podría existir; pero, al mismo tiempo, el Derecho es también lo que hace posible la moral (que podamos actuar como seres autónomos en un mundo tan complejo como el nuestro), y una función esencial del Derecho es la de regular, poner límites y civilizar el poder" (p. 27). El peso que deben tener las razones morales en un sistema jurídico es un debate aparte, que no se aborda en esta ocasión.

Atienza prosigue explicando qué tipo de conocimiento es el Derecho (no es una ciencia), qué habilidades deben enseñarse en la Universidad para preparar a los juristas y, lo más importante, nos habla de la 
transmisión de lo que él llama cultura jurídica y sentido común jurídico, sobre lo que no se darán más detalles para despertar la curiosidad del lector.

En su brillante ensayo ¿Tiene un futuro la filosofía del Derecho? (Con ocasión del homenaje a Jorge Malem), Atienza se basa en la obra de Enrique Gimbernat Ordeig - publicada en 1970, ¿Tiene futuro la dogmática penal? - para reflexionar sobre si los cambios que se han producido en los últimos tiempos en el Derecho suponen una amenaza para la supervivencia de la filosofía del Derecho y, en caso de que la respuesta sea negativa, qué tipo de filosofía del Derecho tiene algún futuro, en el sentido de que cumpla los requisitos para resolver o al menos decir algo que sea relevante en relación con los problemas jusfilosóficos.

Aquí Atienza continúa con su sutil Black Mirror ocupándose de la hipótesis del no-Derecho, ya que no descarta que el control de la conducta de todos o algunos de los homo sapiens (o sus sucesores) deje de ser jurídico en algún momento. Pero, en el futuro inmediato, rechaza que el Derecho vaya a desaparecer (por el contrario, su percepción es que el grado de juridicidad de la sociedad viene aumentando mucho), por lo que, aun con los cambios, seguirían existiendo los problemas jusfilosóficos tradicionales (el concepto de Derecho; el conocimiento jurídico - el método - y la justicia). En otras palabras, el futuro de la filosofía del Derecho parece estar de alguna manera asegurado, aunque no del todo.

Atienza enfatiza que existe un tipo de filosofía del Derecho que, a su juicio, tiene sentido cultivar: para sorpresa de nadie, la de inspiración postpositivista (atención: no confundir con la neoconstitucionalista), que asume la tesis fundamental - encontrada en autores como Dworkin, Alexy, Nino o MacCormick de que el Derecho no es simplemente un sistema de normas, sino, además y sobre todo, una actividad, una práctica social con la que se trata de alcanzar determinados fines y valores.

Como es sabido, esta concepción del Derecho es una de las señas de identidad del pensamiento de Manuel Atienza y ha recibido críticas de diversa índole. En parte, algunas de ellas pueden deberse al carácter aún incompleto de la teoría. El propio Atienza se encarga de dejar constancia de este último aspecto: "Es una idea que he desarrollado ampliamente en trabajos recientes y lo único que me interesa subrayar aquí es que no es una concepción del Derecho que pueda considerarse, ni mucho menos, acabada” (p. 170).

Con elegancia y brevedad, el autor añade que el futuro de la filosofía del Derecho "dependerá fundamentalmente de la capacidad que muestren los jusfilósofos de las nuevas generaciones para 
construir - en no escasa medida, para continuar con - una disciplina académica que logre insertarse eficazmente en la cultura jurídica y sin que esa eficacia signifique renunciar a su-imprescindiblefunción crítica” (p. 170).

Atienza cree que los programas de filosofía del Derecho en las facultades deberían estar diseñados para juristas y no para los interesados en el desarrollo técnico de la materia: los propios filósofos del Derecho (haciendo uso aquí de la famosa distinción de Bobbio entre la Filosofía del derecho de los filósofos versus la Filosofía del derecho de los juristas). Como se ve, su vocación docente no se oculta y en ningún momento el autor pierde de vista a los alumnos.

Acto seguido expone el contenido que debería tener un programa de filosofía del Derecho, con los temas que, a su juicio, serían imprescindibles (o altamente positivos) para la formación de un estudiante de Derecho, para la elaboración de la dogmática jurídica y para el desempeño de cualquier profesión jurídica. El lector deberá acudir al libro para saber cuáles son, aquí sólo se avanza uno de ellos: el proceso legislativo (de producción normativa en general), uno de los temas más estimados por la autora de esta reseña.

En Juristas y zorizos, Atienza retoma la conocida distinción trazada por Isaiah Berlin entre el intelectual (escritor, pensador o ser humano en general) del tipo "zorro" y del tipo "erizo" (también explorada por Dworkin en Justice for hedgehogs). El propio título del ensayo ya adelanta el argumento: la contracción “zorizo" equivaldría a mitad zorro y mitad erizo. Básicamente Atienza sostiene que las profesiones jurídicas requieren las habilidades tanto de los zorros ( "astucia para encontrar una solución adecuada para cada problema, cada situación") como de los erizos ("ser capaz de articular esa solución con razones que la vuelvan - como pasa con las púas del erizo - invulnerable”). Con ello, quiere decirse que el Derecho "requiere una combinación de casuismo y de espíritu sistemático; la habilidad para ser capaz de ver una misma cuestión, un mismo problema, desde muy diversos ángulos y perspectivas, pero sin perder nunca de vista las ideas generales, la unidad, del Derecho; encontrar, como decía, soluciones adecuadas para los problemas prácticos, pero sabiendo bien que esas soluciones tienen que encajar en un cuerpo teórico coherente”. (p. 63).

Para Atienza el método jurídico tiene un carácter dialéctico, consistente en partir de un examen adecuado de la realidad (del problema que se pretende resolver), para después pasar a alguna teoría que se tenga sobre el Derecho y posteriormente regresar a la realidad, al problema. Este tipo de preocupación 
metodológica - aunque venga acompañada de un grado de abstracción lo suficientemente alto como para que nadie (o casi nadie) esté en desacuerdo - es otra de las señas de identidad del pensamiento del autor.

Otra preocupación de su obra se refiere a los aspectos prácticos y contextuales, también presente en el ensayo Siete tesis sobre el activismo judicial, en el que, tras aportar su propia definición de lo que es el activismo (diferenciándolo del perfil deseable de un “juez activo”), Atienza afirma que la calificación de una decisión como "activista" presupone la consideración de las circunstancias teóricas y del entorno social en el que se inserta la actividad judicial. En el ejemplo que pone, una decisión "aceptable" en un país como Colombia no lo sería necesariamente en Alemania, así como también es importante si la decisión fue dictada por un juez ordinario o un miembro de la élite del Poder Judicial.

Para Atienza, sin embargo, considerando el contexto español, no es el activismo la peor patología jurídica, sino el formalismo, que es definido en el ensayo, entre otras características (que para algunos sólo serían una caricatura), como "la concepción que ve el Derecho única o preferentemente como un conjunto de reglas y que rechaza interpretar las normas acudiendo a lo que son sus razones subyacentes” (p. 94). Para Atienza, el formalismo constituye una deformación (un defecto) del Derecho, pues ignora los fines y valores que dan sentido a la práctica jurídica (al para qué se interpreta).

Dice Atienza: “En mi opinión, en un país como España (pero me parece que este juicio puede ampliarse a todos - o casi todos - los países del mundo latino), el principal defecto - casi congénito - de nuestra cultura judicial (y, en general, jurídica) sigue siendo el formalismo. De lo que adolece la judicatura (hablando en términos generales) no es, yo creo, de una tendencia a prescindir de la letra de la ley y a remontarse a principios de filosofía moral y política a la hora de resolver los casos que se le presentan, sino más bien de entender el Derecho de una manera excesivamente estrecha, literalista y formalista”. (p. 96).

El fragmento es provocador, ciertamente despierta la discordia en Brasil y puede parecer chocante, pero no es nada nuevo en sus ideas. De hecho, su distanciamiento del normativismo positivista (el Derecho como sistema de normas) es una decisión consciente del autor que ha marcado su visión del Derecho desde hace mucho tiempo ${ }^{2}$. Para Atienza, la realidad jurídica no es un resultado cristalizado por una

\footnotetext{
${ }^{2}$ Véase por ejemplo: ATIENZA, Manuel; RUIZ MANERO, Juan. Dejemos atrás el positivismo jurídico. Isonomía, n. 27, 2007 , pp. 7-28.
} 
elaboración interpretativa o conceptual, sino un fenómeno social en perpetuo movimiento. De ahí su insistencia en entender el Derecho como una práctica social.

Para él, el positivista "puro" comete el error de concebir el Derecho como una fotografía o una pantalla en pausa, como si ese momento representara toda la película o fuera una realidad autónoma. Para evitar este error, Atienza prefiere presentar el Derecho como una realidad en formación, analizable en términos de fases o etapas de un proceso. Dado que el análisis de las partes es insuficiente, es necesario encadenarlas en la idea del todo en movimiento (la película en su totalidad). Por ello, en su ontología jurídica, presenta el Derecho como una empresa orientada a la consecución de fines y propósitos.

Lo importante de esta idea de Manuel Atienza - y que también aparece, de alguna manera, en los ensayos 'Los jueces crean Derecho', Los principios jurídicos y la ponderación y Diez ideas sobre los derechos humanos - es que todos (incluidos los académicos) están irremediablemente inmersos en esta práctica social del Derecho, les guste o no, y por tanto no hay forma de describir el Derecho sin valoraciones. No es posible mirar el Derecho desde la distancia, sin principios y valores.

La pretendida "pureza" jurídica del observador externo es impracticable, ya que es imposible estar "fuera": todos participan en el juego del Derecho. Una metáfora muy ilustrativa, con la que seguramente Atienza estaría de acuerdo: si el Derecho fuera un partido de fútbol, hasta los comentaristas (o los aficionados que ven el partido desde la grada) estarían jugando.

Con ello, Atienza rechaza los presupuestos epistémicos de que el Derecho no soportaría discusiones valorativas, adoptando una posición clara en la interminable discusión de la teoría del Derecho en cuanto a la separación entre Derecho y moral. Quienes han tenido la oportunidad de convivir más de cerca con él saben que el profesor Atienza suele repetir que es como si los estudiosos con pretensiones meramente conceptuales, analíticas o descriptivas hubieran hecho "voto de castidad", porque "de aquí en adelante no entran" (en las discusiones morales), siempre utilizando un tono sutilmente pícaro y provocando risas entre los presentes.

El ensayo Por qué no conocí antes a Vaz Ferreira es otro ejemplo de las matrioskas que componen la teoría de Manuel Atienza: la teoría de la lógica informal o teoría de los paralogismos (falacias no intencionales) de este jurista uruguayo, cuyo dominio es una poderosa herramienta para resolver problemas de (lo que él llama) la parte especial de la argumentación jurídica. 
Otros dos ensayos del libro son también en forma de homenaje a autores: 'Peripecios'. Sobre la filosofía del Derecho de Rafael Sánchez Ferlosio y Dos juristas, donde rinde homenaje a Piero Calamandrei y a Perfecto Andrés Ibáñez, magistrado del Tribunal Supremo español. Pero, a diferencia de lo que podría parecer, los homenajeados no reciben un tratamiento meramente laudatorio o monotemático. Atienza no deja de exponer sus discrepancias y conectar sus posiciones con las de otros autores, lo que no es sino una de las innumerables muestras de su elevada cultura y profundo dominio de la literatura jurídica (acumulada en más de 40 años de docencia), todo ello cuidadosamente referenciado.

El último ensayo del libro, El Derecho, el Quijote y la compasión, es una joya aparte, aunque quizá exija del lector un mínimo conocimiento de la trama de la obra de Cervantes para su mejor comprensión. Atienza presenta el panorama de los estudios en Derecho y Literatura y utiliza las lentes de este campo para examinar las conexiones de la obra cervantina con el Derecho, destacando una de ellas: la lección moral que se desprende de la lectura de la obra sobre la necesidad de la compasión. A continuación, retoma la definición de Aristóteles de la compasión y analiza sus modalidades, para luego revisar los pasajes en los que está presente esta virtud, incluso sobre la base de los especialistas en la interpretación del Quijote.

Como la reseña ya se ha extendido demasiado, y también hay que dejar que el lector descubra por sí mismo las matrioskas del pensamiento de Manuel Atienza - el cultivo de virtudes como la compasión y las aficiones literarias extrajurídicas son algunas de ellas -, aquí va una firme recomendación de lectura. Ya sea porque Manuel Atienza es un extraordinario escritor cuya elegancia, claridad y brevedad hacen que la experiencia sea gratificante; o porque su último libro Una apología del derecho y otros ensayos es un libro provocador y está lleno de reflexiones instigadoras y que merece ser examinado con detenimiento por todos aquellos interesados en la teoría del Derecho, que deseen ver el Derecho desde su mejor perspectiva y prepararse para desempeñar con excelencia su papel de juristas. 